\title{
Physical Activity Programs for Refugee Somali Women: Working Out in a New Country
}

\author{
Pauline B. Guerin, PhD \\ Roda Omar Diiriye \\ Callie Corrigan, BSpExSc \\ Bernard Guerin, $\mathrm{PhD}$
}

\begin{abstract}
Islamic refugee women from non-westernized countries face a number of challenges in adapting to their new country, especially when that new country is westernized and is not Islamic. Refugees are primarily women and children, so it is important that women be in their best health because they usually bear the responsibility of caring for each other and children, often in very difficult situations. Maintaining or obtaining good levels of physical activity contributes to good health: mentally, physically and socially. At the request of women in the local
\end{abstract}

Pauline B. Guerin, Roda Omar Diiriye and Callie Corrigan were affiliated with The Waikato Institute of Technology. Bernard Guerin is affiliated with the University of Waikato.

Address correspondence to: Pauline B. Guerin, The University of Waikato, Psychology Department, Private Bag 3105, Hamilton, New Zealand (E-mail: drpbgnz@ yahoo.co.nz).

This research was conducted when the first 3 authors were employed at The Waikato Institute of Technology, but Pauline Guerin and Roda Omar Diiriye are now at the University of Waikato and Callie Corrigan is at Sport Waikato.

This research was supported with funding from the Foundation for Research, Science and Technology (UOWX0203), the Faculty of Applied Technology, The Waikato Institute of Technology, and the Refugee \& Migrant Service, Hamilton, New Zealand. Special thanks are extended to the individuals who assisted us in the delivery and organization of these programs, in particular, Stephanie McLennan at Sport Waikato and Chrystel, Abdirizak Abdi and Barbara Redfern from the Refugee and Migrant Service.

Women \& Health, Vol. 38(1) 2003

http://www.haworthpress.com/store/product.asp?sku=J013

(C) 2003 by The Haworth Press, Inc. All rights reserved. 
Somali community, a number of initiatives were taken to increase their opportunities for physical activity. Through interviews, observations and conversations we explored barriers to fitness and exercise, the social, physical, and cultural effects of physical activity, and solutions to facilitate Somali women's access to fitness and exercise opportunities. Physical activity interventions included exercise classes in a community center used by the Somali community, trial memberships at a local women-only fitness center, and walking and sports groups. We discuss the procedural issues relating to setting-up these physical activity opportunities, the results of interviews with 37 of the women about their health and perceptions and issues relating to the physical activity options, and our recommendations for setting up similar classes with other Somali or Islamic communities. [Article copies available for a fee from The Haworth Document Delivery Service: 1-800-HAWORTH. E-mail address: <docdelivery@ haworthpress.com> Website: $<$ http://www.HaworthPress.com> (c) 2003 by The Haworth Press, Inc. All rights reserved.]

KEYWORDS. Refugee, women, exercise, physical activity, gym, fitness, culture, Islam, Somali

According to the United Nations High Commission for Refugees, a refugee is "any person who, owing to a well founded fear of being persecuted for reasons of race, religion, nationality, membership of a particular social group or political opinion, is outside the country of his/her nationality and is unable, or owing to such fear, is unwilling to avail himself/herself of the protection of that country." Somalia has been in a state of civil unrest since 1991 when civil war broke out, causing over $25 \%$ of the population to flee. The majority of Somali refugees are women and children who no longer have a husband or father because of the war. Women and children, when in refugee camps, are often the targets of rape and abuse. While some are fortunate enough to be in a refugee camp for a short time (a few months), many are there for years, some over 10 years, with little hope of gaining entry to a host country.

This paper is focused on Somali women who have been relocated to Hamilton, New Zealand. Such refugee immigrants, and particularly those from non-western countries, face a number of challenges when adapting to their new country. These range from the serious, such as encountering language barriers and discrimination, to what seems less serious, such as how to shop in a supermarket or how to make chocolate cake when one may have never had chocolate cake before. Religious 
differences present yet an additional challenge for Islamic immigrants moving to non-Islamic countries (Berns McGown, 1999; DeKnop, Theeboom, Wittock, \& DeMartelaer, 1996). Refugees may also have experienced a variety of traumatic events that are difficult for service providers to understand and treat (DeSantis, 1997; Watters, 2001).

All these challenges impact on health, and they are exacerbated by the change in lifestyle encumbered by being a refugee. Many of the Somali women in New Zealand have moved from a rural, farming, and labor-intensive lifestyle to an urban setting, which has resulted in increased sedentary behavior (Porter, 2002). An increase in sedentary behavior, coupled with a drastic change in diet, commonly leads to a number of health problems such as being overweight or obese, cardiovascular risk, diabetes, and even mental health problems. In a Western society, such as New Zealand, the access to physical activity opportunities that are familiar or appropriate for Somali women is very limited. While Islamic religion is not a barrier to women's engaging in physical activity per se (DeKnop et al., 1996; Sfeir, 1985), a lack of appropriate facilities and opportunities can constitute a barrier (DeKnop et al., 1996; Lindsay, McEwen, \& Knight, 1987). Somali women also bear the weight of caring for their extended families, and others in the community (Jenkinson, 1999). Poor or less than optimal health of the women can, in this way, be a strain on the whole family and the community (Yoshida, Allison, \& Osborn, 1988).

Developing approaches to address these health concerns that are both culturally and religiously sensitive is a challenge for those who are involved with these groups: practitioners, policy-makers, health care providers, sponsors, educators and other professionals. The increasing Islamic population in New Zealand and elsewhere suggests the need to plan with respect to their religious and cultural issues, and avoid the problems that have occurred in big centers such as London and Toronto (Berns McGown, 1999). Our aim here is to improve the cultural competencies (Sue, 2001) of those trying to improve the exercise of refugee women.

The benefits of physical activity. The wide-ranging benefits of regular physical activity are well documented and include both short-term and long-term benefits (Medicine \& Science in Sports, 2001; Meisler, 2002). Short-term benefits of regular physical activity include increased energy, decreased stress, improved sleeping, and stronger heart, muscles, bones and joints (Pace, 2000); long-term, physical activity increases longevity and decreases risk of heart disease, diabetes, high blood pressure, obesity and development of some cancers (Batty \& 
Thune, 2000; Ministry of Health, 1999a; Pace, 2000). The benefits of physical activity extend to mental health benefits, such as decreasing depression, anxiety and reducing stress (Meyer \& Broocks, 2000; Salmon, 2001). Although physical activity has a number of benefits, it is related to social and economic status, with those in lower social and economic groups less active (Ministry of Health, 1999b). All these benefits are particularly important for Somali women, many of whom have experienced trauma and extreme changes in lifestyle.

Islam, refugees, and health. It is worth saying a little about Islam and health because there are common misperceptions about both the Islamic views about health and the diversity of Islamic views. [More detail can be found in books on Islamic practices, and health-related details in Rajaram and Rashidi (1999) and Rassool (2000).] The importance of health for Muslims is given in the Holy Quran (Koran or Kuran), which guides the daily lives of Muslims (Ghazizadeh, 1992; Rassool, 2000). The importance of dental health, nutrition, sexual health, cleanliness and physical activity is also stressed. Although interpretations of the Quran are varied with respect to physical activity participation for women, the most common interpretation is that physical activity participation is not prohibited for women so long as it is not done at the expense of caring for the family (De Knop, Theeboom, Wittock, \& De Martelaer, 1996). However, some Quran prescriptions can function to limit women's physical activity participation (Sfeir, 1985). As an example, the clothing generally worn for sport and physical activity participation in the West would not be acceptable for Islamic women in most circumstances, and although the wearing of western clothes is not essential for women to participate in physical activity, the social implications of dressing differently from other participants can constitute a barrier to engaging in some forms of physical activity, and it is also sometimes necessary to modify traditional Somali dress for safety reasons when exercising.

Regardless of the importance of health for Muslims, refugees face a large number of health-compromises. There are well-known health-related problems stemming from unemployment, separation from family, a lack of proficiency in English, and their previous experiences in conflict regions (Altinkaya \& Omundsen, 1999; Blakely, 1996; Ekblad, Ginsburg, Jansson, \& Levi, 1994; Pernice \& Brook, 1994; Wooden, 1991). The immediate health problems are that refugees are often in poor physical health when they arrive in their new country (Allotey, 1998; Blakely, 1996; Knipscheer, de Jong, Kleber, \& Lamprey, 2000;), and there can be injuries resulting from war or natural disasters, health 
problems from conditions of hunger and deprivation, and dental and health problems associated with living in refugee camps (Young, Bukoff, Waller, \& Blount, 1987). Finally, eating and exercise practices are typically changed when arriving in a new country, especially to a developed country, making diet and nutrition important health issues for refugees (Burns, 2002). While exercise will not solve all these physical health problems, some exercise will help the overall health levels of the women.

Research conducted with a large Somali community in New Zealand (Guerin, Abdi, \& Guerin, 2003) gave some indications that Somali women were very concerned about weight gains resulting from an increase in sedentary behavior compared to living in Somalia. A few women incidentally mentioned that there was a lot more physical activity incorporated in their daily living in Somalia, especially walking, and that this changed drastically when they arrived in New Zealand (cf. Porter, 2002). This was supported by the finding that the women, in New Zealand, were significantly less likely to leave the house than men, contributing to sedentary lifestyles (Guerin, Abdi, \& Guerin, 2003). Some women also expressed concern in that study that their diet had changed for the worse and that the Somali families had poorer nutrition now, from fast-foods and the lack of availability of traditional ingredients for cooking. While western people's diets may be improved through the use of dietary information on food products (such as fat content), both the type of information and language used are problematic for Somali.

The Guerin, Abdi and Guerin (2003) health survey was not specifically aimed at women's health, and many of the findings about women were incidental. The present research was therefore aimed at devising appropriate exercise for the Somali women in Hamilton, New Zealand, and to interview them more systematically about the constraints, benefits and improvements that might be made. Our aim has been to facilitate Somali women's access to opportunities to engage in more physical activity, and our approach has been an active one: to intervene in partnership with the community and provide such facilities and opportunities.

\section{METHODS}

\section{Location of Study}

The study was conducted in Hamilton, New Zealand, which has a population of 108,000 people of varying ethnic and cultural backgrounds. About $75 \%$ of the Hamilton population is of European ethnic 
background, about $18 \%$ Maori (the indigenous people of New Zealand), and the rest from Pacific Islands, Asia or other countries (Statistics New Zealand, 1996). The main language spoken is English, followed by Maori. The majority of people in Hamilton identify as Christians, although there has been an increase in other religions. There are approximately 850-900 Somali living in Hamilton, but accurate demographics about the Somali population are difficult to obtain (B. Redfern, Refugee \& Migrant Service, Personal Communication, September 11, 2002). Unlike Somalia, Hamilton has a moderate to cold climate.

\section{Participants}

Women in the Somali community initially expressed interest in accessing physical activity opportunities to a male leader of the Somali community. This eventually resulted in three programs for exercise facilitation (described below). Because of the constraints from working with real communities, the programs could not be carried out independently, and there was some membership overlap. The results from all three will be outlined simultaneously.

The average age of the women who were interviewed was 33 years, in the range of 17 to 67 years. The average amount of time living in New Zealand was 3.5 years (range $=2$ months to 7 years). Seventy-five percent of these women had children, with an average of five children (range 1-9). These characteristics were only for the women interviewed, but they are indicative of all the women who participated across the three programs. Although employment and education data were not specifically collected for this group of women, other research (Guerin, Abdi, \& Guerin, 2003), and close involvement by the researchers with the community, suggest that the majority of women in the Somali community are on government benefit programs and are unemployed. Younger women, due to their attendance at school, tend to have better English ability and higher education levels compared with the older women in the community who may have very little or no English ability and very little or no formal education. There is government welfare access to medical care in New Zealand, unlike the USA, but many women do not utilize this often enough since there are barriers to attending (Abdi, Guerin, \& Guerin, 2003).

\section{The Three Exercise Programs}

The three programs were: exercise classes at a community center; a 3-month trial of memberships at a fitness center with a women-only fa- 
cility; and a walking and sport group. These classes were carried out independently of one another at different times of the year.

Community Center Exercise Classes. Arrangements were made to use a community center gym facility. Community meetings were held with the women to negotiate appropriate times for exercise sessions, and arrangements were made with the Manager of the community center to adapt the gym facility for the women's use. This required painting all glass doors and windows so that the women could not be seen during their exercise sessions. The women requested exercise sessions to be held in the evenings three times each week. Between eight and 40 women attended each session which continued for a period of about six weeks and concluded at the start of Ramadan. A total of 16 classes were held and an interpreter was available at the sessions to clarify instructions when necessary.

Gym Memberships. After the exercise classes were finished, a local gym and fitness center with a women-only facility was approached for reduced-rate memberships for Somali women who were interested in using equipment as part of their physical activity routines. The Refugee \& Migrant Service (a non-government organization) subsidized the membership fees, resulting in a cost of only NZ\$5.00 per woman for a 3 -month membership for 20 women in the Somali community. The usual cost would have been NZ\$150 (about US\$75). Women in the community were notified of the opportunity and the first 20 women to pay their dues and fill out membership forms were provided the memberships.

Walking and Sport Group. At the end of the gym memberships, a walking and sport group was organized to be held two times each week, weather permitting. During these sessions, the women met in the evenings, after dark, at a sport field for a local high school. This provided the women a place to walk, jog, play various ball games such as soccer and netball, and to do other exercises. The time of the gatherings was requested by the women themselves.

\section{Data Collection}

The analyses in this paper were drawn from interviews, observations, and casual conversations with women in the Somali community over approximately one year during which these three physical activity opportunities were provided. Overall, more than 100 women participated across the three programs. While the gym memberships were limited to 20 specific women, the other programs were open to the community and 
attendance varied from week to week. The community center classes had between eight and 40 women at any one session and the walking group generally had 6-15 women attending. The community center classes, as the first ones offered to the community, attracted a lot of attention and many women attended only on one or two occasions, possibly just to see what it was all about. Conversations were carried with many of these women at some point, whether or not they were more formally interviewed.

The Interviews. Semi-structured interviews, in the style of Pagtatanong-tanong (Pe-Pua, 1989), were conducted with a total of 37 women following the community center exercise classes $(n=27)$ and following the gym memberships $(n=20)$, approximately eight months apart. Ten women were interviewed twice to get their perspectives on both programs. Interviews included a mixture of open-ended questions, likert-type scale questions, and forced-choice questions with options to comment. The women were asked a variety of questions about their health and their concerns with health, their attendance, how they liked or did not like the exercise classes, what sorts of things they would like to have done differently, the barriers to participation, and about the instructors and style of exercise. The interviews were conducted by a trained bilingual woman from the community who had acted as translator for many of them previously (the second author). The interviews were conducted at a time and place convenient to the women, individually, and in Somali or English, whichever they preferred.

\section{RESULTS}

\section{Physical Activity and General Health}

In interviews with the 27 women following the community center classes, all reported less than 2.5 hours of physical activity in the seven days preceding the interview, with $20 \%$ reporting "no physical activity." When asked, "How often do you participate in sports," all the women reported, "I don't participate in sports." When asked "Do you feel like you need to exercise more or be more physically active?", $96 \%$ of the women said "yes." Two questions aimed at the health perceptions of the women asked "How concerned are you about your health" on a scale of 1-7 ( $1=$ very unconcerned, $7=$ very concerned $)$, and the average was 5.6, with $81 \%$ of the women responding between 5 and 7 . The women were also asked, "Compared with someone else your age, 
would you say your own health, in general, is ..." using a scale of 1 to 7 with 1 as "Poor" and 7 as "Excellent." The mean response was 5.3, with $73 \%$ responding between 5 and 7 . In all, the women reported being reasonably healthy compared to others their age, but being concerned about their health.

In the interviews following the gym memberships, 75\% (15 of the 20) of the women reported being less active now compared to when they lived in Somalia. When asked to explain this, over half of the women $(55 \%)$ referred to the decrease in walking that the women do compared to when they lived in Africa. Thirteen of the 20 women lived in refugee camps prior to coming to New Zealand. Women blamed the higher use of cars for transportation and generally feeling less "comfortable" for their decreased walking:

I am very worried about my health because in my country when you buy meat you have to buy the fattest meat, but later you walk and sweat so all the fat dissolves but here I don't sweat even with the hottest summer. (Age 55)

I used to walk to my farm about 5 kilometers daily and dig. That was enough for my well-being. But here I don't have a farm, if I walk there are too many cars, it's dangerous and sometimes cold. (Age 55)

[In Africa] there was no car so I had to walk or run everywhere. There was no fridge in the house, so I had to go shopping everyday, walking. (Age 23)

Because in the [refugee] camp I had to walk a lot for food, water, and hospital whereby here my brothers drive me everywhere. (Age 23)

\section{Attendance and Enjoyment of Sessions}

In the interviews following the community center classes, women were asked how many of the 16 sessions they had attended. The average number of sessions attended at the community center was 9, with a range of 0 to 16. Only two women interviewed did not attend any of the sessions, and 13 of the 27 women reported attendance at 10 or more sessions. All of the women reported that they knew about the sessions: ten reported hearing about the sessions via the Somali community radio, 11 
had heard about the sessions through a community worker, and the other five had heard through friends or other social networks.

During the memberships at the fitness center, we attempted to monitor attendance through the use of a membership swipe-card system, but we found this system to have a number of flaws. For example, the women often borrowed one another's cards to use at the gym, the swipe system at the gym was often not functioning properly, and if the women forgot their cards, then the visit was not recorded. However, assessment of the swipe-system data, information from the gym staff, and the women's reports of their attendance all indicated that there was a regular attendance during the trial memberships. That is, women attended the gym a few times each week over the three-month period except for two women who signed up but never attended. Attendance at the fitness center was encouraged with information evenings, a number of phone calls, and offers to help with transport.

Analysis of comments to the questions about what they liked most and what they liked least about both the exercise classes and gym memberships showed that, in general, the women enjoyed the sessions. Seventy-five percent of the women reported "nothing" when asked what they liked the least about their gym memberships. Those who did report not liking something, most often mentioned not liking the music (see below).

The most-cited reason for not attending the exercise classes at the community center was looking after children/family, the second reason for not attending was for cultural or religious reasons, and the third most-cited reason was lack of transport. Ninety-six percent of the women wanted to have exercise classes again. When asked what sort of class they would like to have in the future, $76 \%$ said that they would prefer a class for older women only, and the remainder wanted classes with just sports (such as basketball).

In the interviews following the gym memberships, the most cited reason for not attending the gym was childcare responsibilities, followed by transportation problems and illness. No one cited religious or cultural reasons for not attending the gym, which differed from the community center exercise classes. After the gym memberships, most women said that they would like to have walking groups and exercise classes to help them be more physically active.

\section{Problem Themes Arising from the Data}

We found that there is no one-exercise program that is going to work, and there are a number of differences between what younger and the 
older women prefer in terms of exercise options and exercise contexts. Therefore, exercise classes need to be adapted and there needs to be constant consultation with the community. In a close community such as this, however, the consultation must go beyond just the people involved, since there are religious and cultural consequences. For example, at one point a rumor spread that an Imam had spoken out in the Mosque against these women's exercise classes and asked them to stop. Other men who had heard the Imam speak said they had never heard him say anything that resembled this suggestion. Regardless of the truth, this is an example of the very real consequences of getting people to do something different (like exercise classes) that affects the whole community, and cultural competency needs to extend beyond interacting with the participants only.

\section{Cultural and Religious Issues}

Exercising in a women's-only environment. The interviews showed that it was particularly important to the women that they had a culturally "safe" place to exercise, not just for themselves but also for the integrity of their whole community. They required somewhere they could dress appropriately for exercise without fear of men coming into the center or looking into the center. The community center was set up to be private from any outsiders. Investigation of other appropriate facilities in the community found that only two fitness centers were appropriate for use by the Somali women. These facilities were still unaffordable suggesting the need to create suitable venues for exercise classes with any Islamic women's group and this should not be ignored or the time needed underestimated.

Religious issues. Special arrangements need to be thought through for Ramadan. The exercise classes in the present report were cancelled during this period. Longer-term solutions would be to have exercise classes later at night after the women have eaten, or to stop exercise during this period if the remainder of the year was active for the women.

In the interviews following the community center classes, nine of the women $(35 \%)$ commented that they did not like music in the sessions (average age 52) whereas $15(58 \%)$ said that they did like the music or that having music did not matter to them (average age 26). The following are examples of what was said:

Culturally, I did not like to wear track pants; religious, I did not want pop music or the music. (Age 55) 
I don't like music, it is against my religion. (Age 49)

I like the music very much, and that made me enjoy every part of the session. (Age 17)

Of the 20 women interviewed following the gym memberships, only four said that they "hated music" (aged 26, 32, 38, 43). The average age of the women who attended the gym was 36 (range 17-67), compared with those interviewed following the community center classes (average age was 30 , range 17-65). Comments from the fitness center women included:

[The music] was good. It was entertaining and made me forget that I was actually working out. (Age 22)

I don't care [about music] because I don't understand English. (Age 65)

[Music] is not good for religious purposes, but my aim was to get fit in [the gym] not to listen to music. My children watch music. (Age 45)

There was clearly an age difference for the preference of music. The appropriateness or inappropriateness of music in Islam is ambiguous with respect to the authority of the Holy Quran. It is likely that if the older women did not prefer music, they would understandably see music as contributing to their children not following their customs (whether or not it had that effect) and contributing to the breakdown of the community (Berns McGown, 1999). In this case there is no one correct method for cultural competency-it depended on the context.

\section{Safety and Discrimination Issues}

We arranged for walking and sports classes to be held at a local high school sporting field that was in close proximity to the homes of many of the women. The women could walk to the field in small groups. However, because the sporting field had high visibility from the road and was not very private in the daytime, the women themselves asked to schedule these groups after dark. In the dark, the field was very private and the women felt comfortable going there. After dark was the preferred time to hold sessions and our conversations with the women indi- 
cated that they did not want to be watched when walking or kicking a football and the women would even stop playing and turn their backs to the road on the few occasions when a car's headlights shone into the field. Walking on sidewalks was not a preferable option because the women were concerned about derogatory comments, having things thrown at them, and prejudicial jokes being made by some New Zealanders if they were visible. Some felt their bright clothes would make them even more conspicuous if walking in a group of 20-30 women. These fears were exacerbated following the terrorism in the United States on September 11th and sessions were briefly postponed for a few weeks. The local Mosque had been vandalized and rumors spread quickly throughout the community that it was not safe for Muslim women, in particular, to be out of their homes because of their highly visible clothes.

These issues of safety and discrimination are unique in that for most women, walking and playing sports in an empty school field after dark would seem to be the worst possible scenario, but for these women, there was a good social logic to their choice. This again emphasizes that there should be constant consultation about issues and attempts made not to assume too much from a western perspective of cultural competency.

\section{Practical Issues}

Transport. The community center was located in the area of the city where many of the Somali women lived, and the classes were run directly after an English language class also being held at the center. This helped to keep attendance at the classes reasonable, although a number of women had commented that transportation was a barrier to their participation in the sessions. The gym was located at the opposite end of town from where most of the women live, however, making transportation a greater issue for gym attendance.

Childcare. Childcare was the most cited reason for not attending the community center classes and the fitness center. While there was a low cost childcare facility at the fitness center, the fees were still high for the women, and most women were unsure about leaving children there because of uncertainty about how things were run and the care their children would receive. A child-minding scheme within the community would be one approach to help the women get to their exercise classes, although the large number of children might make this difficult. 
Money. The classes held at the community center were free of charge to the women and the gym memberships were low for the 3-months. While this may remove the financial barrier to attend the sessions it might also constitute a motivational barrier to attendance, if women choose not to attend the sessions because they were not paying for it ("so it doesn't really matter if I go"). If they had paid for the sessions, there could be more motivation to attend ("I paid my fees, I better get there"). This speculation, however, requires further research. Others setting up such classes need to consult and talk to the women about this issue as well.

\section{DISCUSSION}

One purpose of the study was to determine the barriers to attendance at physical activity sessions, and procedural problems that occurred. These were seen as an important part of the research documentation in order to allow others to set up sessions in culturally safe ways. Our casual observations and discussions with the women attending the sessions indicated a number of issues that arose from the beginning when setting up the classes.

Language. Interpreters were available for both the community center exercise classes and the walking group, but not necessarily available at the fitness center. Even with interpreters available, it was difficult for many of the women to follow specific instructions (such as aerobic routines) because those who were interpreting were often doing the exercise themselves. The content and instructions of the sessions were therefore simplified to make it easier for all the women to understand, whether they could understand English or not. Once the women became more experienced in these ways of exercising, the routines became more complex.

Religious and cultural factors. Islam suggests that followers pray five times each day, although not all Muslims pray this often. These times correspond with the rising and setting of the sun, and therefore, do not conform to times on the clock, presenting a difficulty with clockbased, western practices. While some Muslims will forego their prayer if they are "in the middle of something," others will interrupt whatever activity they are engaged in to pray. Either way, involvement in activities is not avoided due to prayer, as prayer is an accepted part of life. This was reflected in different ways for the exercise classes at the community centre and at the fitness centre. The availability of the commu- 
nity center and the preferred time for the women coincided with prayer time. This initially resulted in interruptions to the class when some women were praying, but a resolution was soon found by finding an extra room at the center that could be used as a praying room. Similarly, women attended the fitness center at times that suited them, or when they could get a ride and this was sometimes at the same time as prayers. The women accommodated this by using space available in the dressing rooms.

The mental, physical and social benefits of exercise. Our observations and the information obtained from the women indicated that the provision of culturally and religiously appropriate physical activity opportunities benefited the women and the community in innumerable and possibly immeasurable ways. Physically, we found that the increase in sedentary behavior due to cultural adaptations of many of the Somali women has sometimes resulted in extreme weight gain. We found that engaging in the physical activity described here is helping to decrease this weight gain among the women, and improve their physical health (Guerin, Diiriye, \& Corrigan, submitted).

While physical and mental benefits of physical exercise are well noted in the literature, we also noticed benefits of a directly social nature. For example, the positive social interactions and opportunities provided in all of the physical activity sessions described here contributed to the development of social relationships and community cohesion amongst the women. In the case of the gym memberships, it also provided some social interaction with other women in the community who were neither Somali nor Islamic. Our conversations with the Somali women suggested that this was important to them for getting safe exposure to non-Somali women and for spending more time out of the house.

Overall, we found many benefits for the Somali women in the opportunities provided for increasing physical activity. In working with the women of the Somali community we have found that their identification of their needs contributed to the successful programs. We have also found that on-going communication with the women was the best way to provide the opportunities to identify and meet their needs.

\section{REFERENCES}

Allotey, P. (1998). "Travelling with 'excess baggage': Health problems of refugee women in Western Australia." Women and Health 28: 63-81.

Altinkaya, J., \& Omundsen, H. (1999). "Birds in a gilded cage: Resettlement prospects for adult refugees in New Zealand." Social Policy Journal of New Zealand 13: 31-40. 
Batty, D., \& Thune, I. (2000). "Does physical activity prevent cancer?” British Medical Journal 321: 1424-1425.

Berns McGown, R. (1999). Muslims in the diaspora: The Somali communities of London and Toronto. Toronto: University of Toronto Press.

Blakely, T. (1996). "Health needs of Cambodian and Vietnamese refugees in Porirua." New Zealand Medical Journal 109: 381-384.

Brightwell, K. L. (1996). "Sponsorship and refugee resettlement: The Somali experience." Masters of Social Science Thesis: University of Waikato.

Burns, C. (2002). "Moving to Australia could be bad for you health: Food and nutrition issues of Somali women arriving in Australia as refugees." Nutridate 13(2): 5-7.

DeKnop, P., Theeboom, M., Wittock, H., \& DeMartelaer, K. (1996). "Implications of Islam on Muslim girls' sport participation in western Europe: Literature review and policy recommendations for sport promotion." Sport, Education and Society 1: 147-164.

DeSantis, L. (1997). "Building healthy communities with immigrants and refugees." Journal of Transcultural Nursing 9: 20-31.

Ekblad, S., Ginsburg, B-E., Jansson, B., \& Levi, L. (1994). "Psychological and psychiatric aspects of refugee adaptation and care in Sweden.” In A. J. Marsella, T. Bornemann, S. Ekblad, \& J. Orley (Eds.), Amidst peril and pain: The mental health and well-being of the world's refugees (pp. 275-292). Washington DC: APA.

Ghazizadeh, M. (1992). "Islamic health sciences: A model for health education and promotion." Journal of Health Education 23: 227-231.

Guerin, B., Abdi, A. \& Guerin, P. B. (2003). "Health status of Somali refugees living in Hamilton and their experiences with the medical system." New Zealand Journal of Psychology, in press.

Guerin, P. B., Diiriye, R. O., \& Corrigan, C. (2003, submitted). "Body composition and cardiorespiratory fitness among refugee Somali women living in New Zealand." University of Waikato.

Jenkinson, B. E. (1999). Somali women's voices: Being a Somali woman in New Zealand. Masters of Social Science Thesis: University of Waikato.

Knipscheer, J. W., de Jong, E. E. M., Kleber, R. J., \& Lamprey, E. (2000). "Ghanian migrants in the Netherlands: General health, acculturative stress and utilization of mental health care." Journal of Community Psychology 28: 459-476.

Lindsay, K., McEwen, S., \& Knight, J. (1987). "Islamic principles and physical education." Unicorn 13: 75-78.

Medicine and Science in Sports. (June, 2001). [Supplement on effects of exercise]. Medicine and Science in Sports, 33.

Meisler, J. D. (2002). "Towards optimal health: The experts discuss physical fitness." Journal of Women's Health \& Gender-Based Medicine 11: 11-16.

Meyer, T. \& Broocks, A. (2000). "Therapeutic impact of exercise on psychiatric diseases: Guidelines for exercise testing and prescription." Sports Medicine 30: 269-279.

Ministry of Health. (1999a). "Chapter 6: Combined cardiovascular risk factors.” In Taking the Pulse. Wellington: Ministry of Health.

Ministry of Health. (1999b). "Chapter 3: Physical Activity." In Taking the Pulse. Wellington: Ministry of Health. 
Pace, B. (2000). "The benefits of regular physical activity." Journal of the American Medical Association 283: 3030.

Pe-Pua, R. (1989). "Pagtatanong-tanong: A cross-cultural research method." International Journal of Intercultural Relations 13: 147-163.

Pernice, R., \& Brook, J. (1994). "Relationship of migrant status (refugee or immigrant) to mental health.” International Journal of Social Psychiatry 40: 177-188.

Porter, G. (2002). "Living in a walking world: Rural mobility and social equity in sub-Saharan Africa.” World Development 30: 285-300.

Rajaram, S. S., \& Rashidi, A. (1999). "Asian-Islamic women and breast cancer screening: A socio-cultural analysis." Women \& Health 28(3): 45-58.

Rassool, G. H. (2000). "The crescent and Islam: healing, nursing and the spiritual dimension. Some considerations towards an understanding of the Islamic perspectives on caring." Journal of Advanced Nursing 32(6): 1476-1484.

Salmon, P. (2001). "Effects of physical exercise on anxiety, depression, and sensitivity to stress: A unifying theory." Clinical Psychology Review 21: 33-61.

Sfeir, L. (1985). "The status of Muslim women in sport: Conflict between cultural tradition and modernization." International Review for the Sociology of Sport 20: 282-304.

Statistics New Zealand (1996). Hamilton City (Census 96) (1996 Census of Population and Dwellings-Brochure. www.stats.govt.nz accessed 16 October 2002.

Sue, D. W. (2001). "Multidimensional facets of cultural competence." The Counseling Psychologist 29: 790-821.

Watters, C. (2001). "Emerging paradigms in the mental health care of refugees." Social Science and Medicine 52: 1709-1718.

Wooden, M. (1991). "The experience of refugees in the Australian labor market." International Migration Review 25: 514-535.

Yoshida, K. K., Allison, K. R., \& Osborn, R. W. (1988). "Social factors influencing perceived barriers to physical exercise among women." Canadian Journal of Public Health 79: 104-108.

Young, R. F., Bukoff, A., Waller J. B., \& Blount, S. B. (1987). "Health status, health problems and practices among refugees from Middle East, Eastern Europe and Southeast Asia." International Migration Review 21: 760-782. 